Dr. George R. Wiirte, Savannah, Ga., has had two cases of aneurism on which he operated according to Dr. Matas' method. Both were aneurisms of the femoral artery, and both were of traumatic origin; one was caused by a stab wound and the other by a bullet wound. In both instances the operation was carried out successfully, and the patients are now at work and are as well as they ever were. He emphasized the point Dr. Matas made that the operation is not a difficult one if his description is followed elosely.

Dr. Rudolpi Matas said that he deeply appreciated the kind words of encouragement and praise expressed by the various speakers. He said that he realized most convincingly, however, that the good that there is in the method he sug. gested, especially its simplicity and safety, could never have been demonstrated without the coöperation of the 20 American surgeons who, with their characteristic alertness and keenness to test new ideas-as well as by their ability-have so quickly furnished the remarkable evidence which he submitted.

\section{THE VALUE OF X-RAYS IN OCULAR THERAPEUTICS.}

G. ORAM RING, A.M., M.D.

Ophthalmic Surgeon to the Episcopal Hospital, Phtladelphia; Ophthalmologist to the Widener Memorial Home for Crippled Children, Phlladelphia ; Consulting Ophthalmologist to the Alnerican Oncologic Hospital, Philadelphia.

PHILADELPHIA.

Amid the illuminating advances that have characterized the rapid progress of medical science during a trifle more than the last decade, the spectacular and beneficent discovery of Professor Roentgen, of Wurzburg, occupies a position of acknowledged preëminence.

The classical papers which first startled the world of science have been followed by a flood of literature emanating from hosts of enthusiastic workers from almost every corner of the globe, and while the hopes and promises have to some extent failed of materialization yet the amazing therapeutic results that have been wrought up to the present moment should abundantly merit our profound appreciation and study.

Ophthalmic science has had its quota of fleet-footed workers, eager to develop the far-reaching possibilities of the newly discovered form of radiant energy. It is our purpose to institute an inquiry into the results thus far achieved and to attempt to define the present position of the $x$-ray therapeutics as applied to several important branches of ophthalmology.

When we consider the $x$-ray from a therapeutic standpoint we are, according to Freund, ${ }^{1}$ dealing with the following forces emanating from the surface or within a vacuum tube in action: (1) heat, (2) ozone, (3) cathode rays, (4) ultra-violet rays, (5) rays composed of material particles, (6) Roentgen rays, (7) spark and brush discharges from the high tension, electric accumulation on the surface of the tube, (8) electric and electro dynamic waves, (9) waves of unknown character. Stern ${ }^{2}$ believes the only rays that need to be considered are the $x$-rays, the unknown rays and the electric discharges from the surface of the tube.

The histological sequelæ of the $x$-ray application (Stern) are stimulation of the vaso-constrictor nerves of the blood vessels, paralysis of these nerve filaments accompanied by vascular dilatation, edema, the result of

* Read in the Section on Ophthalmology of the Americau Medical Assoctation, at the Fifty-seventh Annual Session, June, 1906.

1. Freund: "Elements of General Radio-Therapy," Vlenna, page 323 .

2. Stern : "Practical Results Accomp!ished by Radiant Energy," New York Med. Jour. March 10, 1906. paralysis carried to a higher degree, and finally complete nerve paralysis, accompanied by distruction of tissue.

It is impossible in so brief a communication to place before you a complete summary of the brilliant work which the electro-therapeutist has achieved, but many opinions of value have been gleaned from the copious, and at times, polemic literature of the last few years. In answer to a communication addressed to many of the foremost ophthalmologists and $x$-ray experts of our country, I am able to present to you a number of hitherto unpublished opinions regarding the results of the application of this form of therapy to disease of the eyes and ocular adnexa. In the discussion to follow I hope that the various and at times divergent views expressed may be crystallized into definite and unfailing methods of technic that may make the amazing results claimed by certain observers a usual sequel of the application of this form of energy.

In a malignant disease of the eyelids and adjacent structures, radiotherapy (because of the favorable character of the resulting cicatricial tissue) finds one of the most satisfactory fields. When Stembeck, ${ }^{3}$ of Stockholm, exhibited before the Swedish Medical Society, a case of epithelioma, which he had cured by means of Roentgen therapy, a stimulus was given to this important work, which, notwithstanding its triumphs, must still be conceded to be in its incipiency.

My experience in a considerable group of epitheliomas, involving the eyelids and contiguous skin structures, and varying in size from a base of $10 \mathrm{~mm}$. in its longer diameter to an extensive ulceration, at times embracing half of the upper and lower lids, and extending well on to the bridge of the nose, several of which were totally inoperable, has been so uniformly satisfying that I am accustomed to leave little doubt in may patient's mind regarding the certainty of a cure. In only one such case that has come under my observation was there any tendency to a recurrence at the end of about eighteen months. This was subjected to a few further treatments and has remained in perfect condition through the succeeding year.

Mayou and D. Walsh (London) presented a most promising series of results before the Roentgen Society, Dec. 2, 1902, the former claiming that all cases of socalled rodent ulcer of the eyelids can be cured. The inflammation which can be produced by the $x$-ray varies, according to these authors, from a mild leucocytosis (stimulation) to an absolute destruction of tissue. Added experience seems to emphasize the opinion, early expressed, that this profound change is largely superficial, and is not produced by the rays that penetrate deeply. It is the function of the leucocytes to break up and remove all irritating substances, or to encapsulate and thus render them innocuous.

One of our foremost authorities, William Allen Puscy (Chicago), reports having treated several cases of epithelioma, in which there was no involvement of the deeper orbital tissues, and all resulted in cure where sufficient treatment was permitted. No relapses have occurred, and some of the cases were treated about three

3. Stelnbeck : Quoted from " $X$-Rays in Cancer and Other Dlseases," by Richard J. Caren.

4. Mayou: "The Use of $X$-Rays in Ophthalmlc Surgery," Archlves of the Roentgen Ray, January, 1903.

5. Pusey, W. A. : "Report of Cases Treated with Roentgen Rays," Chicago Medical Recorder, April, 1902. For Dr. I'usey's technic see Chicago Medical Recorder, April, 1900, and Journal of Cutaneous and Genito-Urinary Diseases, July, 1900 
years ago. John Green, Jr., ${ }^{6}$ St. Louis, Mo., also concludes that in epithelioma and rodent ulcer of the eyelids, $x$-ray therapy surpasses all other methods of treatment and can be relied on to cure all such cases.

Sweet ${ }^{7}$ believes that it is no longer right to resort to plastic operations in these two conditions, basing his judgment on the successful results of 18 out of 20 cases treated.

John E. Weeks ${ }^{6}$ (New York) regards the $x$-ray treatment of very great value in epithelioma and has placed at my disposal the notes of one prizate case of epibulbar epithelioma of very great interest.

The patient, a man aged 54, had a growth occupying the inner half of the ocular conjunctiva to the caruncle, and involved about the inner third of the cornea.

Diagnosis was confirmed by microscopic examination.

About $100 x$-ray exposures were given, extending over a period from March, 1905 to January, 1906; the exposures averaging 7 minutes each at 10 inches from the Gundelach anticathode using a tube of medium tension. Patient is virtually well. Vision 20/40. Tissues of the globe have not suffered. The exposures were made through a tube $11 / 4 \mathrm{in}$. in diameter. There was no other protection.

De Scliweinitz ${ }^{6}$ (Philadelphia) has had four cases of "entire and rapid cicatrization" with no relapse. In two additional cases the results were entirely negative, or possibly the condition was aggravated. In one of the latter, excision was practiced with subsequent application of the rays, without recurrence. De Schweinitz concludes the rays should be tried for a certain period, and if the results are not good, then excision with or without plastic operation should be practiced.

Charles Lester Leonard ${ }^{6}$ (Philadelphia) whose experience has been extensive in treatment of epitheliomas and various skin lesions involving the evelids, regards it as uniformly and permanently successful. Baker (Cleveland) writes that he has had five cases of rodent ulcer with perfect recovery. One case of special interest has been under observation for ten years, but all this time the disease was slowly progressive, not only the eye, but the cheek and temple were involved. The eye was enucleated and, later, $x$-ray applications were made for a year or more less regularly, resulting in complete cicatrization with no evidence of recurrence at the end of four years. In a sixth severe case in which both $x$-ray and radium were used, a complete cure has been effected, the curative agent being, in Baker's judgment, the Roentgen ray. In eight cases of epithelioma, the results have been entirely satisfactory, although in most of the cases the knife was used and followed by the $x$-ray. There have been no recurrences. Baker had two cases of lupus involving the eyelids that have been "very greatly improved if not entirely cured by the $x$-ray."

Hermann Knapp" (New York) has seen "four temporary results in epithelioma and the like." Stevenson ${ }^{\theta}$ (Albert Lea, Minn.) has used the $x$-ray with success in treatment of lupus of the eyelids only. Newcomet ${ }^{\mathrm{B}}$ (Philadelphia) advises me that he has treated about 30 cases, few of which have shown any disposition to recur.

The names of a host of foreign and home workers in ophthalmologic or electrotherapy lines could be added, if additional testimony were needed, among them Hamer, Hall, ${ }^{0}$ Darier ${ }^{10}$ and Bettremieux $;^{11}$ in our own country,

6. Personal note.

7. Sweet, William M. : "Roentgen Ray Treatment of the Eye and Its Appendages." Medicine, April, 1904.

8. Hamer, J. F. X.: "Carcinoma palp. inf. behandel med. $X$ straalen," Ned Tijdskrift $\nabla$. Geneeskunde, 1904, No. 12

$\because$ Hall, Edward: "Rodent Ulcer, Treated by the $X$-Rays," British Med. Jour., Jan. 10, 1903.
Taylor, ${ }^{6}$ Dixon $^{6}$ and Marple ${ }^{6}$ (New York), St. John ${ }^{\natural}$ (Hartford), Holt ${ }^{\boldsymbol{B}}$ (Portland), Black ${ }^{\mathbf{\theta}}$ (Milwaukee), Wescott $^{\boldsymbol{B}}$ (Chicago), Howe ${ }^{\mathrm{\theta}}$ (Buffalo), Schamberg, Hansell, ${ }^{6}$ H. K. Pancoast, ${ }^{6}$ S. Lewis Ziegler ${ }^{6}$ (Philadelphia). Schamberg's case is of considerable interest, as the case involved not only the lids, but the conjunctiva as well. A perfect cure was effected without sign of recurrence at the end of two years.

S. C. Ayres (Cincinnati) has had one case of epithelioma of outer and lower margin of right cornea of six years' duration. It was curetted, but soon recurred. Under $x$-ray treatment, pain was relieved and the condition improved. He was not kept under continuous treatment, and later increase in the growth compelled enucleation.

Bulson $^{\theta}$ (Fort Wayne) advises me that in four cases of extensive carcinoma two were cured, a third probably cured, and the fourth did not continue treatment. Woods ${ }^{\theta}$ (Baltimore) believed the rays successful in preventing a recurrence after an orbital evisceration for extensive carcinomata.

Würdemann ${ }^{6}$ reports a case of carcinoma of the orbit beginning in the skin of the external canthus. The operation consisted of exenteration of orbit and resection with partial removal of malar, superior maxillary and orbital process of the frontal bones. The patient was treated about two years by $x$-rays several times a week; a suspicious sore was removed by secondary operation, and the result was complete cure with full lining of orbit by skin.

\section{X-RAYS IN SEVERE CASES.}

As illustrative of the curative possibilities of the rays in the more extensive carcinomatous involvement of the orbital and adjacent tissues, it is only necessary to refer to cases of which this one reported by Dr. Pusey, ${ }^{5}$ of Chicago, is a type:

Deep Carcinoma in the Orbit.-Patient of Dr. Wm. H. Wilder, treated by Dr. Pusey.

The growth involved all of the structures in and around the orbit, and the terrific intracranial pain seemed to leave little doubt of meningeal involvement.

After nearly two months of treatment and a resulting $x$-ray burn coincident with increasing pain, the case was regarded as hopeless and discharged. About six months later it was found he was still living; the mass had shrunk and lids would close. He is free from pain, eats and sleeps well.

Of the 10 cases so carefully reported by Chas. S. Bull, ${ }^{12}$ two were extensive carcinomata. One was a case of the eyeball and orbit in which operation was advised, but declined. The case was cured by twenty-seven $x$ ray exposures. The other was a case of deep-seated carcinoma involving the nose, eyelids and orbit, likewise perfectly cured by thirty-four exposures.

As noted by George C. Harlan ${ }^{6}$ (Philadelphia), J. W. Pancoast $t^{6}$ and many others, with whom probably all of us are in accord, it must be remembered that in many of the deep-seated growths of the carcinomatous type the rays have totally failed to arrest the disease, but even in such cases there is little doubt of the pronounced anodyn effect of the exposures, and, while, as suggested by Nelson Black (Milwaukee) and others, the deeper the orbital involvement the less favorable result can be expected, yet the estimate of Jackson ${ }^{6}$

10. Darler, A.: "Introduction a l'étude des rayons $\mathbf{X}$ en therapeutique oculaire," La Clin. Ophth., July 10, 1903.

11. Bettremleux (Joubalx): "Rayons $\mathrm{X}$ en therapeutique oculaire," Ibid.

12. Bull. Chas. S.: "The Treatment of Inoperable Cases of Malignant Disease of the Orbit." 
(Denver) that it is of great value even in the more extensive types of orbital carcinoma can be abundantly maintained.

$$
\text { SARCOMA. }
$$

In a previous paper ${ }^{13}$ I considered the use of Roentgen therapy in attacking this form of malignant neoplasm. Reference was made to the remarkable result in L. Webster Fox's case of inoperable sarcoma involving the orbit and accessory sinuses apparently cured by fifty exposures to $x$-ray. A daily treatment of five minutes' duration, with a high vacuum tube placed at 10 in. distance, containing a current of 4 amperes, was maintained for 4 weeks, the frequency of the treatment then being reduced on account of an excessive erythema.

In the same paper the gratifying reports of a number of cases of sarcoma $x$-rayed by Leonard and by Pfahler, of Philadelphia, involving the face, neck, lip, nostril and antrum were accepted as giving promise of similar brilliant results with improved technic, when the growth involved the orbit and surrounding structures. The immediate application of the method was suggested before radical operation was attempted. If unsuccessful in removal of the growth, Leonard, who has had a very wide experience, claims that its virulence will be decreased and the dangers of metastasis lessened. Other methods of attack were carefully considered in the event of failure with the $x$-ray.

I will refer now to a few additional reports of cases treated by the rays as introductory to a further discussion of this important subject.

Beclere ${ }^{\mathbf{1 4}}$ reports the case of a patient affected with sarcoma of the floor of the orbit who was cured by $x$ rays. The disease had lasted four years. Two operations had been performed, the last one including removal of the eye. All other methods of treatment had failed, but improvement set in as soon as radiotherapy was employed. Histologically, the tumor was found to be a malignant sarcoma. Beclere reports an additional case of orbital sarcoma cured by $x$-rays.

Kienbock ${ }^{\boldsymbol{B}}$ reports a sarcoma cured by $x$-rays. This case is of very unusual interest. A growth having appeared in the nose seven years before, in spite of operations oft repeated, had invaded the adjoining structures and produced exophthalmos on both sides with subsequent optic atrophy. Pain ceased after the first treatment, and after thirteen applications the growth (an endothelial sarcoma) entirely disappeared. Eyes resumed their normal appearance and vision partly returned. Grossman ${ }^{6}$ reports a similar case which had almost entirely disappeared under the $x$-rays.

Theobold $^{\mathbf{B}}$ (Baltimore) has had one case of marked exophthalmos (unpublished) with the diagnosis of inoperable sarcoma of the orbit--a diagnosis in which two other surgeons concurred. Under the $x$-ray treatment the case rapidly improved and after a lapse of seven months seemed to be cured. Pfahler ${ }^{8}$ gdvises me that he has treated three cases of primary orbital sarcoma, with resulting disappearance of the growths. A fourth case, which was recurrent, showed no ultimate improvement.

When to these reports we add the case of Mosely, ${ }^{15}$ orbital sarcoma, that of Pratt, ${ }^{15}$ melanosarcoma of orbit,

13. Ring, G, Oram : "Orbital Sarcoma, with Report of a Case and 13. Ring, G. Oram : "Olectrochemical Stertlization," N. X. Med. Jour., June 10, 1905 .

14. Beclere: "Sarcome de l'orbite gueri par les rayons-X," Gaz. des Hop., June 14, 1904 .

15. "Radtotherapy in Ophthalmology," quoted by Allen. that of Harper, ${ }^{16}$ melanosarcomatous pigment areas on the sclera, and that of Fox, ${ }^{17}$ true sarcoma of the lids, all cured by radiotherapy, we surely have abundant reason for some satisfaction at the results already achieved.

Many observers have utilized the rays successfully in preventing a recurrence after the removal of malignant orbital growths, notably sarcoma, and the rerent experience of Wescott ${ }^{6}$ (Chicago) and Chas. S. Bull ${ }^{12}$ and Marple $^{6}$ (New York) will serve to bring to our attention this important phase of the subject. Wescott advises me that he exenterated a case of orbital sarcoma, and, feeling positive that all of the disease was not removed, subjected the patient to $x$-ray treatment for three months. 'There was no evidence of recurrence at the end of one year. On the other hand, Bull, in his painstaking report of eight cases of orbital sarcoma, has not found radiotherapy of value as a curative agent either before or after operation. He, however, believes it distinctly effective in the relief of pain. Marple has had one case of orbital sarcoma with exenteration of the orbit. $X$-ray was used in the effort to prevent a reeurrence, which it failed to do. In one of my own cases it seemed to prevent a recurrence in loco.

\section{TRACHOMA.}

In the treatment of the nodular formations or masses of round-cell infiltration of the conjunctiva, known as trachoma, the ophthalmologist has found one of his most difficult problems. The various remedies used may be classed under the heads of chemical or mechanical irritants. The excessive and often damaging cicatricial tissue remaining after the application of the chemical irritant classes this method as far from ideal.

The rolling, brushing and other allied methods are of unquestioned value, but the cures are frequently incomplete even with the added chemical treatment. The cure is wrought, in part, by mechanically removing the diseased masses and, in part, by the induction of a leucocytosis with subsequent cicatrization. Since the disease is probably allied to lupus, it may be caused by an undiscovered bacillus, the destruction of which by the methods noted results in pronounced betterment.

Stephen Mayou ${ }^{18,4}$ lauds most highly the results achieved by $x$-ray treatment of this condition, claiming (1) less deformity of the lid after treatment, (2) it is practically painless, (3) the pannus clears more thoroughly. His first case, presentel before the London Ophthalmological Society early in 1902, was apparently the initial application of the method. "Instead of the white puckered conjunctiva gaincl by other methods, a supple non-contracted, non-scarred conjunctiva, with no obliteration of the fornices," was noted. In every one of 15 cases a perfect result was achieved. No burning of the globe occurred in any case. Two-minute exposures were given from four to six successive days, followed by a week's rest; then came semi-weekly exposures until slight photophobia began. When granules disappear, the treatment should cease, as the infiltration induced by $x$-ray will be some weeks in subsiding. The patient is seated 9 inches from the anode with a moderately soft tube and a current of 6 amperes. The metal mask formerly used is now discarded, as the patient is not exposed sufficiently to get any skin reaction.

16. Harper: "Melanosarcomatous Pigment Areas on Sclera," Amer. X-Ray Jour., 1902, p. 1164.

17. Quoted by Wirdemann.

18. Mayou: "The Treatment of Trachoma by X-Rays," Trans. of the Ophth. Soc., London, S. 10. 
Stevenson and Walsh ${ }^{19}$ selected severe cases which orlinarily required a very prolonged treatment by old methods, and they were cured in a few weeks. They report equally good results in a case treated less than two months with a high frequency current. After twentythree painless applications of the brush discharge from a vulcanite elcctrode connected with a Cox's d'Arsonval apparatus, a lisease disappeared that would have lingered on two or three years under ordinary treatment.

Walsh ${ }^{20}$ (London) has treated four cases of severe louble trachoma, with ccmplete cure in two and marked improvement in the remaining two. Good effects were. the same if lids were closed or ererted.

Vassutinsky"1 obtained favorable effects on trachoma by means of the Roentgen rays. These rays diminished the infiltration, caused the disappearance of the granula. tions and of the pannus, and produced a pronounced improvement in thes ubjective signs of the malaly. As a rule, however, trachomatous granulations disappeared but slowly under the influence of Roentgen therapy. 'The rays proved to be harmless in treating the eyes, no evil effects were noted in any case, nor was pain experienced by the patients. The author thinks that the rays are of service in cases in which ordinary methods of treatment fail.

Ruggero Pardo ${ }^{22}$ reports two cases of trachoma which derived benefit from the application of the r-rays.

CASE 1.-The patient, aged 60, had suffered from double trachoma for three years. In the right eye was dense pannus, abundant catarrh, and congested iris. The left eye was similarly affected, but to a much less degree.

CASE 2.-The patient, aged 14, had had trachoma two years. A Crookes tube with a spark about $700 \mathrm{~mm}$. was used at a distance of 45 to $30 \mathrm{~cm}$. for four to ten minutes at a time. Only one eye was treated, the other being carefully protected with a metallic shield. About six applications were made in each case at intervals of three days. As a result of the treat. ment the conjunctiva became smoother, the secretion ceased, the pannus cleared, aud there was marked improvement in vision in the first case. In the second case many of the tarsal follicles disappeared, the secretion diminished, aind there was considerable improvement in the subjective sensations.

Geyser ${ }^{23}$ maintains that a few exposures, six to ejght, will suffice to bring about a perfect cure. In important consideration is to causc absorption and stimulate normal nutritional processes; nothing secms to answer the purpose any better than the direct contact of the tissues wit ha high-frequency racuum tube generated by a static machine or $x$-ray coil. (omplete dictails of lechnic are given in the article.

Horniker and Romanin ${ }^{2 *}$ ('Tricste) report the history of three successful cases of trachoma treated by $x$-rays. The methods of Mayou, Cassidy, Rayne and Pardo are compared. The method of Mayou of applying the rays directly to the everted lids was selected, as the strength of current did not have to be judged with such exactness in order to prevent skin lesions. Cassidy and Rayne applied the current to the closed lids. Notwithstanding the care exercised, dermatitis of the hands de-

19. Stevenson and Walsh: "On the Curative Treatment of 'I'rachoma by the X-ray Tube Exposure," Medical Press, 1903.

20. Walsh : Medical Brief, No. $31,673,1903$, also Lancet, No. 10 p. 237,1903 .

21. Vassutinsky : "Roentgen Rays in Trachoma," Roussb vatch, Jan. 8, 1905.

22. Pardo: "Cases of Trachoma Treated by Roentgen Ray," Gnz. d. Ospedall, Milan, No. 13, p. 1193.

23. Geyser, Albert C.: "The Successful Treatment of Elghteen Cases of Granular Lids by the $\mathbf{X}$-ray and HIgh Frequency Vacuum

Currents," Jour. of Advanced Therapeutics, May, 1904

24. Horniker and Romanin : Zeltft. f. Augenblk., 1904 veloped and, for the purpose of holding open the everted lids, Romanin devised an instrument which is carefully described and which is said to make the performance perfectly comfortable to physician and patient. He claims that one single advantage of the Pardo method which makes prominent the retrotarsal fold can likewise be obtained by his instrument by placing a compress behind the everted lid and by turning the lid holder by screws. Although eminently successful in three cases, Horniker does not attempt to decide on its final value until a larger mass of authoritative material shall have been collected.

The investigation of Heineke $\mathrm{H}^{25}$ as to the results of the application of the $x$-rays in disease of the spleen and other lymph organs in rabbits, more particularly in leukemic conditions, pointed to a destruction of lymphocytes in the follicles.

Buschke and Schmidt ${ }^{26}$ found a cessation of proliferation of cells in kidneys and testicles, which confirmed the earlier findings of Albers Schonberg ${ }^{27}$ concerning itzoospermia. These results induced Stargardt ${ }^{28}$ (Kiel) to investigate the results of the rays on trachoma mass, which is essentially composed of lymph follicles.

Kuhnt (Königsberg) has practiced excision of the upper retrotarsal folds for many years. It was at his clinic that Stargardt was permitted to $x$-ray the folds before excision. In the application the method of Kienbach was modified; that is to say, one long exposure (twelve minutes with soft tube distance of $5 \mathrm{~cm}$.). Stargardt believes there is no danger to the conjunctiva in these exposures. Microscopically the principal change was noted in the follicles. In one instance the retrotarsal fold was excised in $\mathbf{1 6}$ hours; in a second, 30 hours; in a third, in 14 days. In the first and second cases highly colored masses were scattered over the whole follicle which were regarded as the remains of destroyed nuclei. These masses varied in shape and size from that of a lymphocyte to that of the smallest particle. They were mostly strongly colored with the stain, a few less intensely so, though very scarce some were non-stained. These masses lie mainly between the cells, partly in the phagocytes. The phagocytes are similar to the Villard type. Their number is increased. They are unevenly distributed over the whole follicle and do not show the regular arrangement usually seen in trachoma. In addition to the increase of phagocytes, a strong increase in Villard's giant cells was also noted. The giant cells are very plentiful, and we also find from three to six large black colored nuclei which lie in a mass of plasma substance. The decrease of threads priduced by the segmentation of cells was very striking.

Cassidy and Rayne ${ }^{29}$ (Baltimore) report the case of an artist's helper who suffered for nine years from granular lids.

Patient had been operated on twice with grattage and twice by avulsion. The usual astringent and caustic treatment was also exhausted. Treatment was begun November 8, 1902, through closed lids. Cautious tentative exposures of three minutes each, separated first at intervals of ten days, then five days,

25. Helneke: "Ueber die Finwirkung der Rontgenstrablen auf in nere Organe." Munch. med. Wochft., 1904, p. $\mathbf{7 8 5}$

26. Buschke and Schmfdt, F.: "Tferversuche über die blologischen Wirkung der liontgenstrahlen," V. Inter. Dermatologen-Kongress, Berlin.

27. Albers Schonberg: “Ueber eine blscher unbekannte Wirkung der Rontgenstrahlen auf den Organismus der Tiere," Mïnch. med. Wochft., 1899.

28. Stargardt, K.: "On the action of Roentgen Rays on the Trachoma Follicle," from the Eye Clinic in the University of Kön. lgsberg in Prussia, Zeitft. A Augenhk., 1905.

29. Cassidy and Rayne: Jour. of Eye, Ear and Throat Diseases, 1903 . 
then tri-weekly exposures were given at a distance of 12 inches, and a spark gap of one-sixteenth of an inch. These treatments causel excessive lacrimation which diminished on successive exposuros and finally ceased. By the thirty-fifth exposure both eyes were free from trachomatous granules. The patient's lids are now little inflamed and are not thickened. The mucous membranes are still red, but free from swelling and discharge. There are absolutely no trachomatous granules, photophobia is entirely absent, and the patient uses her eyes constantly without discomfort.

The effect, according to three writers, is neurotrophic. Normal tissues are stimulated to a new vigor, and pathologic tissue, always being of less resistance, assumes a retrograde metamorphosis.

At a regular mecting of the Philadelphia County Medical Society, Nov. 23, 1904, W. S. Newcomet and J. P. Krall ${ }^{30}$ (Philadelphia) exhibited a girl of eighteen who had been subjected to all the operations for the cure of trachoma without success.

Patient was treated with the $x$-ray from July, 1903, until January 1,1904 . The inflammatory reaction was so intense that it was thought better to abandon the treatment, Later, however, it was found that she could count fingers at close range. The cornea of the eye was entirely clear and only with special illumination could fine blood vessels be seen. The eye not treated with the $x$-ray showed all the symptoms that the treated eye formerly exhibited. The condition of the patient had been present since infancy, and she had been unable to see across the room. Treatment was given every other day for five minutes for about six weeks, when a burn developed and treatment was withheld. Newcomet believed the result to be due to the accidental burn produced in the course of treatment.

H. N. Bishop ${ }^{31}$ (London) gives the results of electrical treatment of trachoma at the Middlesex Hospital. Cases had been treated with well equipped apparatus, with rays, high-frequency currents, and radium. With regard to the $x$-rays he explains that there were two sets of rays emanating from the tube, (1) the $x$-rays proper, (2) the overflow rays that cause the severe burning of the skin which sometimes occurred. The former of these rays were used. Four cases of trachoma were treated in this manner. Two were young women. In one, fifty applications were made in five months. The right eye showed changes that might reasonably have been produced in this time without treatment, while the left, which was at first unaffected, steadily got bad. The disease subsequently cleared up in the usual manner with bluestone. None of the three other cases did any better. The seven cases treated with high-frequency currents did not improve at all.

Kassabian $^{6}$ (Philadelphia) has treated four cases in his work at the Philadelphia Hospital, two acute and two chronic. All of the photophobia and lacrimation markedly manifest in the acute cases disappeared after four or five exposures and the results achieved in all four cases were so satisfactory that Kassabian believes we have in the $x$-ray a most valuable curative agent, if properly used. Kassabian's technic in treating cases of trachoma consists in covering the Crookes' tube with a dark cloth and darkening the room. He uses adhesive plaster to fix the lids and expose the surface of the eye, to prevent the burning of the nurse's or assistant's fingers. He covers the face with a leaden sheet and treats one eye at a time through an aperture in the lead. Rapidity of action is obtained by getting the patient to keep the eye open while under treatment. There is less

30. Newcomet and Krall: Trans. Phlladelphia County Med. Soc. Nov. 23, 1904.

31. Bishop, Harman N.: "Electrical Treatment of Trachoma," British Med. Jour., Aug. 26, 1905. danger of burning the cornea than there is to the skin of the eyelid, but should a slight corneal haziness result it quickly disappears and a corneal scar will be absorbed.

W. Franklin Coleman ${ }^{\theta}$ (Chicago) says that in 12 cases of trachoma his results in the treatment have been so uniformly favorable that he would not consider any other method. Coleman's first case was exposed to the $x$-ray July 1,1903 . The disease was of 20 years' standing. A high-frequency tube was used with ten minutes' exposure three times weekly. A perfect recovery resulted in six weeks. He now uses a two and a half inch spark, ten minutes' exposure at six inches with low tube, with lids closed and no mask. Every case treated has resulted in perfect cure.

Ayres $^{\circ}$ (Cincinnati) reports one severe case of trachoma with marked hypertrophy of conjunctiva. Three other cases, trachoma, less severe, all resulted in perfect cure. Pfahler ${ }^{6}$ (Philadelphia) has treated 15 cases of trachoma with $x$-ray. All showed improvement, a few decided improvement. Hc believes the rays should be used after accepted methods have been given a fair trial. He has never seen any harm result to the eye from the exposures.

Schamberg' (Philadelphia) has treated one case at the Polyclinic Hospital with most satisfactory results. There were pronounced vegetations on the tarsal conjunctiva. Pain was relieved and the vegetations disappeared. In this case the eyelids were averted and the rays applied directly to the granulation. Twenty-five treatments of five minutes' duration were given twice weekly.

Jackson $^{6}$ (Denver) advises me that in his experience $x$-ray does some good and may cure acute cases, but not more quickly or certainly than older methods. It has not cured or permanently benefited the bad cases. L Webster Fox ${ }^{6}$ (Philadelphia) has utilized $x$-ray, but not with encouraging results. Fox prefers the older recognized remedies. Suker ${ }^{6}$ (Chicago) states that the $x$-ray has given him no results or even encouragment in treating trachoma of any type. de Schweinitz ${ }^{6}$ (Philadelphia) regards the results as fairly good in the few cases in which he has used the method, but considers his experience too limited to render an expression of his opinion of value. Ordinary therapeutic agents or operative measures have served him as well. With improved technic and exact dosage, the measure offers a prospect of success and should be given the fullest trial. His personal experience is limited to two cases, neither of which was as much benefited as it would have been under ordinary treatment in the same period. He has seen two cases in the care of colleagues in which the results were somewhat better than those that follow the usual applications and surgical procedures. Sweet (Philadelphia) has treated a number of cases of trachoma by the $x$-rays, but did not consider the results to be any better than could be secured by the usual local measures.

VERNAL CONJUNCTIVITIS.

The utterly unsatisfactory results of all forms of treatment of this extremely intractable type of conjunctival hypertrophy determined Allport ${ }^{32}$ (Chicago) to test the $x$-ray in a case of characteristic palpebral type.

The patient, a young lady, aged 19, living in a refined and wealthy environment, gave a history of seven years' experience with the disease. The growths were first amputated, then

32. Allport: "A Case of Vernal Conjunctivitis," Ophthalmic Reeord, October, 1903 
subjected to about eighty $x$-ray applications in less than three months. Photophobia, redness, itching and irritability were removed at once, and the patient apparently perfectly cured, since she has gone through two subsequent summers without any recurrence of the disease.

The case was $x$-rayed by Pusey, and the diagnosis confirmed by Casey Wood, Woodruff and Guilford, Chicago.

Pusey $^{6}$ has had one additional case in which the disease was cured. William Campbell Posey (Philadelphia) believes that $x$-ray exerted decided influence on the course of the disease. He has kindly placed at my disposal a brief note of his case.

The patient, a man, aged 35, came to the Wills Eye Hospital in May, 1905, with the statement that for two years preceding, during the warm months, his eyes had annoyed him greatly with itching and smarting, increased lacrimation and great sensitiveness to light. These symptoms had subsided with the appearance of cold weather again in the autumn. On examination, it was noted that the patient was suffering from a typical attack of vernal conjunctivitis of the palpebral type, the conjunctiva being greatly infiltrated and whitened, and there being a number of flattened granulations in the conjunctiva of the upper lid. The bulbar conjunctiva was unaffected.

Antiseptic washes of boracic acid and cocain, and solutions of adrenalin, in strengths varying from $1-10,000$ to $1-5,000$, were prescribed. The patient was instructed also to report to the Polyclinic Hospital for the administration of the $x$-rays. These were continued during the summer months, the applications being made twice a week, and each seance lasting about five minutes. Subjective symptoms were apparently greatly influenced by the rays, for notwithstanding that local treatment was interrupted for a time, the itching and smarting sensations were much less in severity. After some weeks treatment the follicles underwent a change and became markedly less pronounced. While during the preceding August and September the patient had suffered great annoyance, these months were passed in great comfort. No deleterious action from the rays, either on the eye or adnexa, was manifested at any time.

Zentmeyer $^{\circ}$ (Philadelphia) has had two cases of vernal conjunctivitis treated by means of $x$-ray by Sweet, one resulting in perfect cure, the second in marked improvement.

In the first of Zentmeyer's cases, a boy of 15, the affection was in both eyes, but worse in the right. The upper lids were studded with typical flat granulations. At the limbus above and to the temporal side were the nodular swellings overlapping the cornea. When treatment was stopped, a year ago, the granulations had entirely disappeared from the lids, but a few of the nodules persisted at the limbus. He passed through last summer without any discomfort and at the present time the palpebral surfaces of the lids are normal. The few nodular swellings still remain, but have not increased during the year. The boy was so satisfied with his improvement that he did not return for further treatment.

Sweet ${ }^{6}$ had two remaining cases, which disappeared from treatment after the subsidence of acute symptoms. de Schweinitz ${ }^{6}$ (Philadelphia) has utilized $x$-ray in only one case of vernal conjunctivitis. The treatment was of short duration, and the negative result ought not to be utilized in any estimate of the value of this agent in treating this form of conjunctival diseases. Suker $^{6}$ (Chicago) has had sufficient experience to convince him that $x$-ray treatment of vernal conjunctivitis is of positive value. Jackson ${ }^{\theta}$ (Denver) believes that $x$-ray sometimes diminished the discomfort, but prolonged trial has shown no curative influence.

\section{CONGENITAL NEVI.}

At this writing I am having treated a case of nevus of the left upper eyelid, which had attained considerable proportions. There is apparently being effected a rapid cure.
Stewart (Thomas S.) and Given (Ellis V. W., Philadelphia) advise me they have likewise had several apparent successes with the rays.

\section{CHRONIC CONJUNCTIVITIS.}

By courtesy of Kassabian (Philadelphia) I am enabled to add to the various types of cases amenable to $x$-ray treatment that of chronic conjunctivitis.

The patient, a man, aged 35, had suffered for seven years, with an obstinate type of this condition. Every important method of treatment had been exhausted by the two distinguished surgeons, Knapp of New York and Jackson of Denver, whose patient he had been. At the suggestion of Dr. Schneideman of Philadelphia, and with the added recommendation of Knapp and Jackson, $x$-ray treatment was begun in June, 1904. During all treatments the eyes were open, there were no signs of dermatitis, the lashes and brows were not the least affected by treatment. Patient is perfectly well. He insists on exposing both eyes to the rays once a month for five minutes, which Kassabian regards as unnecessary, considering the cure complete.

In the language of Kassabian, the technic is as follows:

Induction coil (15-incu spark producing) energized with 110voil current, mechanical interrupter 2 amperes going to primary coil. Crookes' tube with "medium vacuum" anode being at a distance of 12 to 15 inches $(30$ to $38 \mathrm{~cm}$.). The face and cliest were covered with a sheet of lead through one opening of which the patient looked towards the tube during exposure. 'Treatments were given for the first three consecutive months twice a week, the time of exposure being gradually increased from one to two minutes. On September 19, 1904, after twentyfour exposures, the condition was greatly improved; the conjunctiva had become pale on the eye that was treated. During October, November and December treatment was continued only once a week, exposure two and one-half minutes. Treatment was discontinued for two months (January and February, 1905 ) and begun again March 1, with an exposure of three minutes once a week. Blood vessels are very small and fine, conjunctiva pale and white. Regular treatment was continued three months longer.

\section{GLIOMA.}

Hilgartner ${ }^{\mathbf{3 3}}$ gives a brief note of a most extraordinary result of Roentgen ray treatment in a case of double glioma in a child aged three and one-half years. The growth in the right eye largely filled the vitreous and could easily be seen in its incipiency in the left eye. Pain was severe. Eighty-four exposures were given. Right eye shrank to two-thirds of its natural size and the growth in left eye was entirely absorbed.

Pusey's ${ }^{33}$ results have been sufficiently encouraging to warrant his urging the use of the rays after removal of glioma and sarcoma to prevent a recurrence.

Würdemann ${ }^{6}$ reports one case of glioma beginning in retina and extending to orbit, maxillary antrum and nasal passages. Three exenterations of the orbit were performed. $X$-rays were finally used for one year with a result of hindrance of development and absolute prevention of pain.

\section{GUMMATA.}

Parker, F. C. ${ }^{6}$ (Norristown) reports a most interesting case of bilateral gumma of the orbit in a child eight years of age. Diagnosis was confirmed by microscopic examination, specific and $x$-ray treatment were both instituted, and it was Parker's opinion, based on the course of the case and its final cure, that the Roentgen ray applications were of very positive value.

33. Quoted by Pusey and Caldwell: "Wherapeutics of Roentgen Iray," 609. 
SCLERITIS AND EPISCLERITIS.

Pardo $^{22}$ in his long and interesting communication believes the results of $x$-ray in scleritis and episcleritis represent a real discovery inasmuch as at present there is no other direct therapeutic agent but only means amounting to a purely symptomatic treatment.

\section{CORNEAL ULCERS.}

Dennett ${ }^{34}$ reports having observed that ulcers of the cornea are stimulated to rapid healing by the rays. Williams ${ }^{34}$ reports a case of flat leucoma in the lower half of cornea. Exposures were given once a week for three months, then twice a week for two months, after which the scar was smaller, smoother, and less dense and vision improved.

\section{UVEITIS.}

Jackson $^{6}$ (Denver) is utilizing the rays in traumatic uveitis. Several times they have given immediate relief from pain and seemed to bring about rapid improvement. In other forms of uveitis he has not seen any marked effect from it.

$$
\text { TUBRICULOSIS OF CONJUNCTIVA. }
$$

\section{Sidney Stevenson ${ }^{35}$ reports the following case :}

A poorly nourished, pallid child, aged 4, was placed under treatment November, 1902. Trachoma-like material was tound in semilunar fold. Lid was half closed and thickened lower palpebral conjunctiva was strewn with miliary granulations and folds of coxcomb like tissue. Similar changes were in the superior retrotarsal fold. Tubereular bacilli were found locally. There were positive results from inoculation experiment. Thirteen $x$-ray exposures of ten minutes resulted in complete cure of the conjunctival disease. Enlarged submaxillary glands were present and were removed by operation.

\section{CAUTION IN USE OF THE RAYS.}

It is important that a note of warning should be sounded regarding the possibility of unlooked for results of a serious character which are said by competent observers occasionally to follow $x$-ray exposures. They would seem to indicate the very great importance of referring our cases to none but experts in Roentgen therapy. I have seen several cases of temporary corneal haze, conjunctivitis and marked episcleral congestion, but all such conditions subsided with the cessation in the use of the rays.

Dr. Henry K. Pancoast, chief of the $x$-ray department of the University of Pennsylvania, warns us regarding the possibility of the induction of severe conjunctivitis, ulceration and opacity of the cornea, edema of the conjunctiva and lids and optic neuritis. If the growth overlies the eyeball a hard rubber, ivory or metal eye spatula may be inserted under the lids.

In one of Sweet's cases of rodent ulcer the application of the rays was followed by the dulling of the mental faculties the following day. Wild reports a case of epithelioma in which the $x$-ray treatment was followed by the development of panophthalmitis, necessitating the removal of the globe. This must be regarded as a result so exceptional as to be unique.

Birch-Hirschfeld believes the rays capable of leading to very serious results if not skillfully applied. In his experiments on rabbits he believes he has certain proof of the existence of blepharitis with loss of hair and eyelashes, conjunctivitis keratitis profunda, and iritis. Some cases showed evidence of optic atrophy. The microscope in certain instances revealed degeneration of the ganglionic layer of the retina. In four clinical cases,

34. Quoted by Allen: "Radiotherapy in Ophthalmology."

35. Stevenson: "Tuberchlosis of Confunctiva," Boston Med. Jour. 1903 , p. 1313 . marginal keratitis with vascularity was noted. These serious changes would seem to be the outcome of too lengthy exposures to the action of the rays. Indeed, Pusey of Chicago in one of his excellent early papers remarks on the possibility of producing atrophy of such highly differentiated epithelial structures as the retinal rods and cones, and regards the production of an inflammation of the conjunctiva as quite as likely as that of the skin structure. Hallopeau and Godaud ${ }^{\mathbf{3}}$ found the patient experienced a disagreeable impression of bright light after long exposure.

Subcutaneous extravasations of blood are said to have resulted in several instances, and Ehrmann quoted by Charles S. Bull described a telangiectatic appearance as a late result of $x$-ray exposure. A few cases of sarcoma and carcinoma by Burdick, Butler, Culey, Edwards and Pusey have been reported in which exacerbations of pain occurred as the result of the exposures.

\section{CONCLUSIONS.}

1. $X$-ray therapy marks a great advance in the treatment of superficial epithelioma and rodent ulcer of the eyelids and can usually be relied on to effect a cure.

2. If unsuccessful then electro-chemical sterilization may be utilized, or finally excision with or without plastic operation.

3. $X$-ray treatment has proven of value in the more extensive orbital carcinomata, but it is conceded that the deeper the growth the less favorable will be the result.

4. A sufficient number of cures of sarcoma of lids and orbit have been reported to warrant its exhaustive trial in all types of this disease. More radical operative procedures with subsequent ray applications being indicated in event of primary failure.

5. $X$-ray treatments usually exert an anodyn influence on malignant disease of the eyelids and orbit, but are occasionally reported to cause exacerbations of pain.

6. Noteworthy progress in the treatment of trachoma has been effected by the utilization of $x$-ray therapy. It should invariably be utilized if ordinary methods fail.

$\%$. The weight of evidence indicates the positive value of $x$-ray treatment of vernal conjunctivitis.

8. There is evidence which points to the value of $x$-ray therapy in chronic conjunctivitis (Kassabian), scleritis, episcleritis (Pardo), traumatic uveitis (Jackson), conjunctival tuberculosis (Stevenson), corneal ulceration (Dennett), glioma (Hilgartner and Würdemann) and gummata (Parker).

9 . It is believed that the rays will cure malignant disease involving the cornea and conjunctiva, provided treatment is applied sufficiently early.

10. The treatment of congenital nevi by the rays is likely to prove effective and should be exhausted before electrolysis or radical operation is considered.

11. Further testimony must be accumulated before an authoritative statement is possible of the effect of $x$-rays in painful types of iridocyclitis and glaucoma and other ocular diseases.

\section{DISCUSSION}

Dr. George S. Dixon, New York, said that we have been for some time, and are still, passing through the experimental stage of Roentgen therapeutics, and that the earlier and many of the later, ideas of the greatest number of workers in this line must be toned down considerably. So much is heard about the success, but nothing at all of the failures, as few men care to acknowledge defeat, and for this reason the time for juilging the exact value of any therapeutic measure is delayed. 
Dr. Dixon said that his therapeutic use of the $x$-ray about the eye has been confined to the treatment of epithelioma, carcinoma, sarcoma and lupus. In epithelioma of the lids his experience has not been at all satisfactory. In cases in which the epitheliomatous growth was of the flat thin variety, not involving the deeper layers of the skin, the results were fairly good, but even after they had apparently been eradicated by the application of the ray they have recurred in from a few weeks to 13 months. In cases of epithelioma of nodular form, involving the deeper layers of the skin, and especially if they involved the deeper parts of the lid, the tarsus, for instance, the growths recurred rapidly after having been broken down and healed, or there was no benefit at all. In this connection he ealled attention to an interesting point, which he had not scen mentioned and which was discovered accidentally: In a patient with an epithelioma of the nodular form on the right lower lid, the growth was accidentally bruised while under $\mathrm{x}$-ray trentment. Treatment was continued, and Dr. Dixon was rather surprised to find that the bruised portion of the tumor healed with remarkable rapidity, leaving a smooth scar with no trace of the growth beneath. This led to an experiment on the remaining nodules on the lid. By means of Knapp's trachoma forceps the remaining nodules were crushed. The lid is now almost well, though still under treatment.

In another patient, aged 44, with a tumor of the same character, the result was not so gratifying. The bruised tissue healed rapidly and a smooth scar resulted, but as rapidly as the tissue was broken down and healed the growth extended further into the surrounding skin, but not so rapidly nor so prominently as before. The invasion was probably inhibited by continued treatment. These two are the only eases in which Dr. Dixon has tried his method, and it is at least questionable whether or not it is good practice. He is inclined to think that the danger from metastasis may be considerable and probably outweighs any benefit that may be gained by crushing and healing the tumors in this manner. It has occurred to him that possibly the greatest value of the $x$-ray as applied therapeutically to the are is in the treatment of extensive epibulbar epithelioma.

In two such cases the growth disappeared after about six months' treatment. The applications were made every other day with a medium low tube at a distance of nine inches, a Friedlander shield being used on the tube during all the exposures, which would average about seven minutes each. Periods of rest were occasionally allowed. In one case a new growth appeared suddenly in practically a new location and resisted the most persistent treatment. The $x$-ray had not the slightest effect on it and the man was finally discharged. A portion of the growth was excised for examination. Dr. Dixon hoped to find that it had reverted to papilloma, but it was still epithelioma.

In a case of recurrent carcinoma a small nodule was dis. rovered in the orbit above the inner canthus. This is gradually becoming smaller, it can now just be felt and that is all. The case is still under treatment and there is no indication of recurrence. Dr. Dixon has treated a number of cases of sarcoma of the lid and orbit, and believes that the treatment of such growths with the $x$-ray is worse than useless because of the loss of valuable time. He has seen no beneficial result ex. cept a slight temporary decrease in the size of the tumors, and considerable amelioration of the pain, and he does not feel that the $x$-ray should be used except in inoperable cases. The only other affection about the eye which he has treated with $x$-rays is lupus vulgaris; it responds very readily. In reference to the remarks of Dr. Ring under the head regarding cinution in the use of the rays, Dr. Dixon stated that it would seem that individual idiosyncrasy enters more largely into this question than the kind, condition or distance (of course excluding very short distances) of the tube or the intensity of the ray. He has had true conjunctival inflammation in but one case and he had not noted either visual or mental effects except that occasionally a patient will complain of slight vertigo immediately after treatment, but it soon passes off. $\mathrm{He}$ is inclined to believe that at least some of the untoward effects ascribed to the $x$-ray may have been mere coincidences.

DR. W. F. Coleman, Chicago, stated that in his experience the use of the $x$-ray has been mostly in twelve cases of tra- choma. There was recovery and for a year at least no recur rence. He said that exposure six inches from a low tube twice a week for ten minutes at a time does not entail any risk. In his earlier experiences he has had the hair entirely disappear but it recurred in six weeks; when this happens the patient has been over-rayed. Dr. Coleman agreed with Dr. Ring on the positive side of this therapeutic measure. The failures, he said, are apt to be due to faulty technic. Physicians may say that they have treated a patient, but without explaining in detail their methods the negative results are unreliable.

Dr. Charles S. Bull, New York, stated that he thinks ne has been a little misunderstood as regards the value of the $x$-ray in cases of malignant disease. He thinks that it is a most important, perhaps the most valuable remedy we have in the treatment of superficial carcinomata. The deeper the disease becomes, the less value, in his opinion, is this treatment. In the inoperable cases of malignant disease of the orbit and sinuses this treatment is of great value in lessening the severe pain which does not return if the treatment is continued, but he has never seen any actual disappearance of recurring growths involving the sinuses, or in inoperable primary growths any beneficial results in the way of checking the disease. He is still hoping that as we Iearn more of the use of these rays we may yet get some hold on the deep sarcomatous tumors.

DR. Jorn E. WEeks, New York, mentioned the tolerance of the retina to the $x$-ray. In the case referred to by Dr. Dixon, the patient had a large number of exposures at a distance of ten inches from the anode of the $x$-ray tube and the retina has not been found in any way affected. Vision is just as good as when the treatment was begun. Dr. Weeks thinks that this is something that is well worth knowing.

Dr. EDWARD Jackson, Denver, in referring to the treatment o: malignant disease, said that he has had one patient with recurrent epithelioma of the lid, recurring within a few months after excision, treated with the $x$-rays, that nas now been free from evidence of disease for five years. But he thinks the cases that most strikingly illustrate the value of the method have been some unsuccessful cases, one in particular that has been under observation for five years, a carcinoma starting in the caruncle. It was excised when as large as the end of the little finger; and the pathologist reported that it was a malig. nant growth and would probably recur early. Only three weeks elapsed before it was evidently growing again. The $x$-ray was used, it checked the growth and led apparently to complete absorption. There remained a little nodular tissue in the scar. Dr. Stover, who applied the $x$-ray, thought there was no need to continue it further, but it was used a month or two longer. Then the ray was discontinued for six or eight months. During this time the patient was not under observation continuously and toward the end of the period the growth was evidently recurring. Treatment was resumed and the growth was again checked. Months later there was a slight increase in spite of the $x$-ray and again the tumor was excised. Again there was recurrence and the ray is still used. Dr. Jackson feels certain from watching the course of the case that the patient has lived three or four years longer than she would have lived without the employment of the $x$-ray and in complete comfort, so far as the pain is concerned. There is now quite a growth at the inner side of the eyeball. In another case in which caustics had been used and in which the eyeball was functionally destroyed, he enucleated the globe to get at the depth of the orbit. It was a slowly growing epithelioma said to have started at the inner canthus. It has now been about eighteen months since he saw the case. There is an opening into the ethmoid, lesions on the brow, and others about the ear. Several of these have healed completely and all apparently are shrinking. These cases, he said, strikingly illustrate the value of the $x$-ray. With regard to trachoma, he said that we can judge the value of any treatment by the mild cases. In the cases which have shown resistance to other methods the $x$-ray has not proven itself so good as older methods in his hands. He has tried it in several cases of vernal conjunctivitis, and, while it has produced comfort and sometimes temporary improvement, he thinks that as a cure it is worthless. 
Dr. A. R. BAkER, Cleveland, states that he has had a number of eases of epithelioma in which he thinks the $x$-ray has brought about recovery. He has seen several cases of sarcomatous tumors involving the sinuses in which there has apparently been no benefit, except in the relief of pain, except in one case of adenosarcoma involving the septum of the nose. $\mathrm{He}$ reported the case six years ago as recovered, but it recurred and an extensive operation was done, removing the growth and as much tissue as possible; in a few months there was recur$r \in$ nce involving the ethmoid and sphenoid sinuses. In consultation with some of the best surgeons it was decided that the case was an inoperable one, and it was turned over to an $x$-ray specialist and to the surprise of every one the patient recovered. That is five years ago and the patient is apparently enjoying good health now.

Dr. JoHn Green, JR., St. Louis, said that he has recently had under observation a case which illustrates the partial failure of the $x$-ray. A woman, aged 65 , was operated on about thirteen years ago for mammary cancer. Six years ago she developed a cutaneous ulcer over the right ala nasi, which increased in size and resisted caustic applications. Finally a series of $x$-ray exposures succeeded in controlling the disease at that site. About two years ago, the disease oegan at the inner third of the right upper lid. Dr. Green saw her first eighteen nonths ago at which time there was complete immobility of the lid, with destruction of a portion of the margin. He reterred her to a competent $x$-ray therapentist who instituted treatment. In the course of the thirty seances the tumor become so much smaller that the patient could voluntarily raise the lid. In the meantime, however, a nodule appeared at the upper inner angle of the orbit which increased in size despite continuous applications of the ray. Operation was advised t.ut refused.

Dr. CASEY A. Wood, Chicago, added his testimony to that of Dr. Jackson's as to the value of the rays in the treatment of malignant tumors that are essentially fatal. He particularly referred to two he has had of secondary gliosarcoma following glioma of the retina. He had the usual experience in enucleating a number of eyes for this disease, but in one case he did an extensive evisceration and had the $x$-rays used afterward. In spite of the rays, however, the secondary tumor occurred as usual and came up to the margin of the orbit, but he was not called on for two years to do another operation, and he thinks that is of great importance. The value of the $x$-ray should not be forgotten in relieving pain and preventing the horrible edema. It helps along until the time when the meninges become affected and the patient dies from secondary invasion of the brain. If it does not cure it is at least of value is an agent of relief.

Dr. C. D. WescotT, Chicago, referred to the case of sarcoma of the orbit mentioned by Dr. Ring in which the ray was used three months and the patient was living at the end of a year. He stated that the patient is still living at the end of three years. Dr. Wescott saw the patient about a year after enucleation of the eye for sarcoma. There was a good-sized tumor which he removed by subperiosteal exenteration. The actual cautery was used on the tissues which could not be removed with scissors and curette and then the patient was subjected to the $x$-rays for three months.

Dr. W. B. Marple, New York, stated that he had one case of recurring sarcoma in which an exenteration of the orbit was done and subsequently the $x$-ray was applied to the orbital tissues. The result was entirely negative and the growth promptly recurred.

Dr. William Sweer, Philadelphia, said that he has had a number of cases of carcinoma, granular lids and vernal conjunctivitis, some of which recurred because the patients failed to return for treatment after the superficial ulcerated area had healed. Although the skin surface was completely healed, there remained a hardened mass at the site of the growth, showing that while the disease had been relieved temporarily, there were still some of the cancer cells deeply situated. In the treatment of sarcoma in the deep orbital structures Dr. Sweet said that we must not forget that active treatment without sufficient drainage is dangerous to the patient. The $x$-rays have a destructive action, and in extensive disease proper drainage must be provided, otherwise the system will be unable to elimate the broken-down tissue. Dr. Sweet has treated a number of cases of trachoma, but has failed to secure results sufficiently satisfactory to warrant the use of the rays in this disease. He has had three or four cases of vernal conjunctivitis, all of which were benefited by this treatment. One boy had typical granulations on the under surface of the lids and around the cornea. The surface of the lids became perfectly normal under the treatment and the granulations at the limbus decreased in size and number although they have not entirely disappeared.

Dr. L. Webster Fox said that since the $x$-ray plant has been established at the Medico-Chirurgical Hospital it is being used in all cases of superficial and deep growths in and about the eyelids and orbit. The first important case that was placed under such treatment was the one queted by Dr. Ring. Since then there have been three similar cases with like results. The first evidence of benefit in these cases was the diminution in the size of the swelling and relief from pain. The first patient suffered so much that she was unconscious at times, and tetany was very pronounced. It was only with large doses of opium that rest and quiet could be obtained. After four or five applications of the $x$-ray the relief from pain and swelling was marked, and continued so throughout the treatment, until all swelling and pain disappeared. In that case, however, the patient has since had metastatic sarcoma of the liver, which caused her death. As regards the inoperable cases of sarcoma of the orbit, he said the $x$-ray should always be given a thorough trial. In the superficial cancers (the epitheliomata) the usual good results, ending in a cure have been obtained. Quite recently a case came under Dr. Fox's observation, in which two-thirds of the upper lid was destroyed. He scraped the tissues thoroughly and applied the $x$-ray for several weeks, by which time all evidence of induration had disappeared. Over this denuded surface he transplanted a flap of skin, which united perfectly. At the Medico-Chirurgical Hospital 100 cases of various inflammations of the lids trom the dispensary were placed at the disposal of the $x$-ray therapeutist-the results were not satisfactory. Other means, such as grattage, sometimes bring about better results. Dr. Fox's method is to evert the lids and with a piece of ordinary gauze scrub the surface, and he thinks that the results are just as good, if not better, in the soft gelatinous papules as by any other method. He has at present an interesting case of leukosarcoma of the iris in which eight applications have been made and it looks as if the disease were slowly disappearing. If a cure can be brought about in this case it will be remarkable. Here one can observe the action of the $x$-ray directly through the transparent cornea on the growth which is now about the size and shape of a grain of wheat.

Dr. C. L. Leonard, Philadelphia, said that he is glad to note that the ophthalmologist appreciates the use of the $x$-ray and believes that it should be used by the $x$-ray therapeutist. If surgeons would appreciate that more and the medical men too they would secure better results. In the deeper growths one is able to secure perfect results. These results are coming, but they will only come with further development of technic, which we do not possess at the present time. We can hardly expect, he said, to reach the deep-seated growths that have already produced metastases. One $x$-ray specialist said that he does not consider a patient cured of malignant disease until he has died of something else and autopsy shows that the malignant disease is not there. Patients often remain apparently well for three or four years and then have recurrences. This method produces results not by removing diseased and normal tissue but by restoring the normal though altered metabolism. The cosmetic result is much better. One can not replace the hair follicles if they have been destroyed. Dr. Leonard has a patient now in whom the upper lid was more than half involved and the hair follieles were destroyed; the patient is well, but the hair can not be restored; otherwise the eyelid is like the other. Dr. Leonard agreed with Dr. Ring and Dr. Sweet that we must get rid of the broken-down tissues produced by the rays. The production of toxemia is proof of efficient treatment, but is also an indication for the cessation of treatment. The $x$-ray therapeutist learns that he must get near the production of that toxemia, but he must have 
drainage for the byproducts caused by the destructive process. When this is done he is approaching as closely as possible to the destruction of malignant disease and restoration to normal We are destroying the disease in situ. The work is not yet perfected and we must get better results, he said, before we speak of cures. In these deep-seated growths the relief af forded by the $x$-ray treatment is a blessing to humanity. Relief from pain in these cases is constant. The patient is free from suffering without the use of narcotics which destroy the sense of perception.

Dr. D. L. EDsall, Philadelphia, declared that he is so much impressed with the importance of recognizing the great potency for harm, as well as for good, in the $x$-ray, that he should desire to emphasize the point again. A year ago in reporting the tirst observations that he made on the effect of the $x$-ray on metabolism, he said that it is undoubtedly the most violent known agent used for therapeutic purposes, and that this demonstrates both great possibilities for good and great potential. ity for harm. Since ophthalmologists do not purposely use the $x$-ray for its general effect on metabolism, the possibilities for harm are to them of more especial importance in this regard. As indieating such harmful possibilities, he would say that he has been so unfortunate as to see, in one of his own cases and in two cases of colleagues, violent general systemic reactions to a single application of the $x$-ray. Two of these cases soon ended fatally, largely as the result of the $x$-ray exposure; while the third patient became almost moribund, but finally recovered. The last case, he emphasized especially, for it was one of chronic rheumatoid arthritis in which the direct exposure was merely to one arm from the elbow downward and it was only five minutes in duration. There was no direct ex. posure of the trunk, although there was a distant diffuse exposure of the whole body, as the parts not purposely exposed were not protected from exposure. This shows clearly that a very mild exposure may have an exceedingly dangerous result. He emphasized also the fact that this patient was already somewhat ill from a chronic cystitis and that the clinician in charge of him, who is a very careful man, did not recognize that the severe illness following the exposure was due to the action of the $x$-ray. Dr. Edsall, however, feels confident that it was due to this, because in a previous observation he had noted exactly the same conditions of metabolism as those which appeared in this case, in a case in which there was certainly a general violent reaction to the $x$-ray. This demonstrates also, he said, what many persons have already come to admit: namely, that occasionally dangerous reactions occur as the result of exposure to the $x$-ray, and that their relation to the $\boldsymbol{x}$-ray has in many instances been entirely overlooked. It is not at all surprising, he said, that violent toxic reactions may occur as the result of $x$-ray exposures. The observations that he has made show that one exposure, even, may double the metabolic output in the next few hours; and, clearly, the necessity for metabolizing and excreting such an amount of destroyed tissue must be dangerous in a good many instances. He said that he did not desire to arouse general opposition to the use of the $x$-ray. It has been too clearly shown that it is occasionally a therapeutic agent of great temporary, and perhaps of permanent, value, and is of unquestionable diagnostic importance. He would insist, however, on the importance of em ploying it for therapeutic or diagnostic purposes with less recklessness than has characterized its use by many of the profession hitherto. In cases such as ophthalmologists meet it is, as a rule, sufficient to protect all parts except those that are purposely exposed; but he considers that it is extremely important to do this, in order to avoid occasional dangerous general reactions, and even if toxic reaction does not occur, we should avoid giving an unnecessary general dose of an agent that always does more than merely take a picture or influence superficial lesions. In the cases that fall into the hands of the medical clinician, the matter is even more important. In such instances, Dr. Edsall believes that it is of great importance that the patient's general condition should be thoroughly known before referring him to the $x$-ray specialist; and a careful conclusion should be reached as to whether he is a proper subject to expose at all to the $x$-ray.

Dr. G. O. Riva, Philadelphia, said with reference to Dr.
Dixon's remarks on the treatment of superticial epitheliomata that his own results were somewhat at variance, inasmuch as in all of his cases there had been complete and comparatively rapici cicatrization. He had no experience with the crushing of the nodules previous to the application of the $x$-ray. He felt that Dr. Coleman's experience in the treatment of trachoma was entitled to full consideration, as the technic had probably been faultless. He would unquestionably use the rays in any intractable case. He entirely agreed with Dr. Bull as to the present limitation of the ray treatment in deep scated carcinomata and sarcomata. He has had only two cases of sarcoma, one in which there was no recurrence in loco, and another whirh is now under treatment; the patient is doing well, the tumor being reduced about three-fourths. Dr. Ring has had only one case of sarcoma of the iris in which there was a question of diagnosis as to one of those rare forms of congenital syphilis, tuberculosis or sarcoma. It was treated with antisyphilitic remedies and with tuberculin without result. $X$-ray treatment was begun and carried on daily, and in three weeks the growths in the iris, which had been increasing, promptly began to disappear. Two of the original nodules could be watched through the clear cornea and have now practically gone, and the third is beginning to lessen. In conflrmation of Dr. Weeks' observation on retinal tolerance to the $x$-ray, he had not seen any ease in which the retina showed any untoward result. Dr. Ring expressed the hope that the brilliant result in Dr. Baker's clearly inoperable case involving the accessory sinuses might with perfect technic and exact dosage be the usual sequel to the application of Roentgen therapy. Dr. Ring said that it was his purpose in the opening of the discussion to have made reference to Dr. Zentmayer's case of vernal conjunctivitis. He gave the doctor credit with using the words "perfect cure" when he preferred the word "inhibited."

\section{THE ECONOMIC ADVISABILITY OF INAUG- URATING A NATIONAL DEPARTMENT OF HEALTH.* \\ J. PEASE NORTON, PIr.D.}

Assistant I'rofessor in Political Economy, Yale University. NEW HAVEN, CONN.

This is an age of progress, intellectual, social and, above all, material-of progress so colossal that the cternal forces of Nature are gradually abandoning the long fight and one by one surrendering to the mind and hand of man. But with all that has been wrought there yet remain broad gaps in our organization which, if left unheeded, may blight the civilization itself. In the present paper an attempt is made to point out what may be regarded as the most serious hiatus in our social system and to consider a possible remedy based on more efficient organization. Societies, like skillful capitalists, should strive to invest their revenues so as to yield maximun returns. When returns are direct and may be charged for, experience has shown that the management in many cases may be judiciously entrusted to private individuals. When social investments produce conditions rather than commodities, indirect services impossible to measure as they occur unit by unit, but which nevertheless result in large substantial gains measurable in the aggregate, the management must be entrusted to national agencies, sufficient in magnitude to produce the rcsults desired.

In an age of great things, a civilization must not be staggered by its own creations. Greater and greater things must it do because of the necessity that compels it. To falter is to lose grip, and to lose grip means a more or less slow destruction of the civilization by divers melancholy wastes.

* Read before the American Association for the Adrancement of Science, thaca, N. Y., June 30, 1906 . 